\title{
Knowledge, Attitudes, and Beliefs Regarding the COVID-19 Pandemic Among Women in Kansas
}

\author{
Talah Bakdash $^{1}\left[\right.$ Courtney Marsh ${ }^{2}$
}

Accepted: 23 April 2021 / Published online: 14 May 2021

(c) The Author(s), under exclusive licence to Springer Science+Business Media, LLC, part of Springer Nature 2021

\begin{abstract}
The COVID-19 pandemic brought forward the challenge of dispersing accurate medical information to the public rapidly. Credible and non-credible sources may impact public reactions to the virus. The purpose of this study is to assess those reactions of women located in or near Kansas. A survey was conducted in July 2020 with questions on knowledge of COVID-19, attitudes and behaviors towards COVID-19, and primary sources of information. 305 survey respondents met criteria for further analysis, and descriptive statistical analyses were applied. Participants were generally knowledgeable of the pandemic, with a mean knowledge score of 11.40 out of 13 (SD 1.3). The attitude statement with the highest rate of agreement was that "social distancing is an effective way of controlling COVID-19 spread" $(\mathrm{n}=265,86.9 \%)$ and that with the highest rate of disagreement was, "I am not worried about my friends" and family members health" $(\mathrm{n}=253,83.0 \%)$. The mostimplemented behaviors as indicated by participants were avoiding contact with sick individuals and washing hands with soap and water often $(n=294,96.4 \%)$, and the least implemented was avoiding meat consumption $(n=257,84.3 \%)$. Finally, most participants indicated that health officials were their primary source of information $(n=215,70.5 \%)$. Participants of this survey had fairly good knowledge of the virus. Attitudes of participants as a whole may be described as cautious without being overly fearful. Reported behaviors also align well with current public health recommendations. These responses may be reflective of where participants are receiving their information, which, for the majority, is from public health officials.
\end{abstract}

Keywords COVID-19 $\cdot$ SARS-CoV-2 $\cdot$ Knowledge $\cdot$ Attitudes $\cdot$ Beliefs

\section{Introduction}

The first known case of coronavirus disease (COVID-19) was documented in Wuhan, China in December of 2019 [1]. By March 11, 2020, it had spread so widely that the World Health Organization labelled COVID-19 a global pandemic [2]. With severe acute respiratory syndrome coronavirus 2 (SARS-CoV-2) being a novel virus, little was known about it and the disease it causes. Information on viral features, transmission, and clinical presentations has been and continues to update as more research is conducted [3].

Talah Bakdash

tbakdash@kumc.edu

1 The University of Kansas School of Medicine, 3901 Rainbow Blvd, Kansas City, KS 66160, USA

2 Department of Obstetrics and Gynecology, The University of Kansas Medical Center, 3901 Rainbow Blvd., Kansas City, KS 66160, USA
The uncertainty surrounding the pandemic, particularly in the first few months, as well as the continually updated information has created room for various responses by the public. These may manifest as differences in knowledge of, attitudes towards, and behaviors with regards to COVID19. This variability in responses is nothing new, however. Past studies on attitudes, beliefs, and practices for previous epidemics, such as Ebola, also demonstrate a lack of consensus in the populations studied [4, 5]. This means that public perception may not always correlate well with the latest knowledge and recommendations outlined by the organizations leading the responses to these epidemics. A lack of awareness of or compliance with current guidelines may have important ramifications for controlling disease spread as well as mitigating public fears.

Investigation of individuals' current knowledge, attitudes, and beliefs may aid in gauging how well the dispersal of information has been received by the public and by what means. A recent study surveying individuals in Kansas demonstrates the high level of knowledge and compliance this 
population has [6]. This study aims to expand on that by detailing the specific facts and opinions that are more contentious among females in Kansas as well as the behaviors they are less likely to comply with.

\section{Methods}

\section{Recruitment}

The target population for this study was English-speaking women aged 18 years or older who had previously accessed The University of Kansas Hospital System (TUKHS). Through the Pioneers Research Participant Registry, which provides the contact information of individuals who have consented to be contacted for research, the survey was sent to 1000 women who met this study's criteria and accessed TUKHS in December of 2019. The survey was sent using REDCap (Research Electronic Data Capture) to ensure responses were non-identifiable, and individuals had 16 days to submit their responses. The timeframe allotted for survey participation was between July 15 and July 31, when COVID-19 case rates were relatively stable in Kansas [7]. 325 individuals participated in the survey; 9 of these participants were male and 11 did not complete the survey. These individuals were excluded from analysis leaving a total of 305 participants.

\section{Survey Design}

A questionnaire was designed with specific sections for demographic information, knowledge, attitudes, behaviors, and primary sources of information.

The true or false statements within the knowledge section took into consideration the current knowledge on COVID-19 as of July 2020.

The statements within the attitude and behavior sections were constructed based off past and current literature on these same constructs [8-16]. The format of these questions was a 5 -point-Likert scale.

Finally, included in the survey was a question on participants' primary sources of information where they were allowed to select multiple sources.

\section{Data Analysis}

Descriptive statistical analysis was used for each survey item. Total knowledge score was described using mean and standard deviation. The remainder of the data collected are categorical and described using percentage rates.

\section{Results}

\section{Participant Characteristics}

This study included a total of 305 females. A summary of their demographics is shown in Table 1 . The majority of participants were above the age of $50(n=218,71.5 \%)$ and white $(\mathrm{n}=276,90.5 \%) .70 .3 \%(\mathrm{n}=184)$ of the population have received a Bachelor's degree or higher and $81.6 \%(n=249)$ were not healthcare workers. Income and employment status varied. Almost all participants $(\mathrm{n}=278,91.1 \%)$ had not contracted or been exposed to COVID-19 at the time they took this survey, though $38.4 \%$ $(n=117)$ had a friend, relative, or acquaintance who had been. Most individuals $(n=217,71.1 \%)$ indicated that they had a condition that put them at risk for COVID-19 complications.

\section{Knowledge}

Participants generally had good knowledge of COVID-19 with a mean score of 11.40 out of 13 (SD 1.3). The knowledge statements with the highest rate of correct answers were regarding COVID-19 transmission via respiratory droplets $(\mathrm{n}=300,98.4 \%$ answered correctly) and a lack of vaccine availability $(\mathrm{n}=300,98.4 \%)$. The statement with the highest rate of incorrect answers $(n=134,43.9 \%)$ was regarding virus survival time on surfaces. Statements regarding COVID-19 fatality, treatment, and creation followed with higher levels of incorrect rates. Percentages of correct and incorrect answers for all statements are shown in Table 2.

\section{Attitudes}

The statement with the highest level of disagreement was "I am not worried about my friends' and family members health" with $83.0 \%(n=253)$ of individuals either disagreeing or strongly disagreeing. This was slightly higher than the $76.1 \%(n=232)$ of individuals who disagreed with not being worried about their own health. However, the statement with the highest rate of strong disagreement only $(n=168,55.1 \%)$ was "I think the response to the COVID-19 pandemic has been overblown." On the other end, most people agreed that "social distancing is an effective way of controlling COVID19 spread" $(n=265,86.9 \%$ agree and strongly disagree) and that "COVID-19 presents a serious threat to the public" $(n=263,86.2 \%)$. More variability in responses or neutrality was shown in regards to the healthcare system's and United States' ability to control the virus. Percentages of responses for each attitude statement are shown in Table 3. 
Table 1 Participant demographic data $(\mathrm{N}=305)$

\begin{tabular}{|c|c|}
\hline Characteristic & Participants, n (\%) \\
\hline \multicolumn{2}{|l|}{ Age } \\
\hline $18-29$ & $6(2.0)$ \\
\hline $30-49$ & $81(26.6)$ \\
\hline $50-64$ & $106(34.8)$ \\
\hline $65+$ & $112(36.7)$ \\
\hline \multicolumn{2}{|l|}{ Race/ethnicity } \\
\hline White & $276(90.5)$ \\
\hline Hispanic or Latino & $6(2.0)$ \\
\hline Black or African American & $13(4.3)$ \\
\hline Native American or American Indian & $2(0.7)$ \\
\hline Asian or Pacific Islander & $3(1.0)$ \\
\hline Other & $5(1.6)$ \\
\hline \multicolumn{2}{|l|}{ Education level } \\
\hline Less than high school diploma & $1(0.3)$ \\
\hline High school or equivalent & $24(7.9)$ \\
\hline Some college, no degree & $63(20.7)$ \\
\hline Associate degree & $33(10.8)$ \\
\hline Bachelor's degree & $91(29.8)$ \\
\hline Master's degree & $72(23.6)$ \\
\hline Professional degree & $13(14.3)$ \\
\hline Doctorate degree & $8(2.6)$ \\
\hline \multicolumn{2}{|l|}{ Healthcare provider? } \\
\hline Yes & $53(17.5)$ \\
\hline No & 249 (81.6) \\
\hline No answer & $3(1.0)$ \\
\hline \multicolumn{2}{|l|}{ Employment status } \\
\hline Employed full time (40+hours/week) & $111(36.4)$ \\
\hline Employed part time (<40 h/week) & $28(9.2)$ \\
\hline Unemployed (looking for work) & $9(3.0)$ \\
\hline Unemployed (not looking for work) & $26(8.5)$ \\
\hline Student & $1(0.3)$ \\
\hline Retired & $116(38.0)$ \\
\hline Unemployed & $13(4.3)$ \\
\hline No answer & $1(0.3)$ \\
\hline \multicolumn{2}{|l|}{ Income } \\
\hline Less than $\$ 10,000$ & $4(1.3)$ \\
\hline$\$ 10,000-50,000$ & $75(24.6)$ \\
\hline$\$ 50,000-100,000$ & $89(29.2)$ \\
\hline$\$ 100,000-150,000$ & $55(18.0)$ \\
\hline$\$ 150,000+$ & $46(15.1)$ \\
\hline I don't know/prefer not to say & $36(11.8)$ \\
\hline \multicolumn{2}{|l|}{ COVID-19 Exposure: personal } \\
\hline Yes & $27(8.9)$ \\
\hline No & $278(91.1)$ \\
\hline \multicolumn{2}{|l|}{ COVID-19 Exposure: acquaintance } \\
\hline Yes & $117(38.4)$ \\
\hline No & $187(61.3)$ \\
\hline No answer & $1(0.3)$ \\
\hline \multicolumn{2}{|l|}{ At risk for COVID-19 complications } \\
\hline Yes & $217(71.1)$ \\
\hline No & $88(28.9)$ \\
\hline
\end{tabular}

\section{Behaviors}

The behaviors that most participants indicated they implemented were avoiding close contact with sick individuals ( $n=294,96.4 \%$ total of "always" and "often"), washing hands with soap and water often $(n=294,96.4 \%)$, and social distancing 6 feet away from others $(n=284,93.1 \%)$. In contrast, the least-implemented behaviors included avoiding meat consumption $(n=257,84.3 \%$ total of "never" and "rarely"), cancelling or postponing doctor's appointments $(\mathrm{n}=201,65.9 \%)$, and disinfecting groceries and mail $(n=188,61.6 \%)$. There seemed to be more mixed opinions for avoiding leaving the house and avoiding getting takeout. Parentages of responses for each behavior statement are shown in Table 4.

\section{Sources of Information}

Participants were allowed to select more than one option as their primary source of information. The most commonly selected source was health officials at $70.5 \%(\mathrm{n}=215)$ and the least commonly selected source was friends or family at $16.1 \%(n=49)$. Figure 1 demonstrates total percentages for each source.

\section{Discussion}

\section{Principal Results}

With very little knowledge about COVID-19 at the start of its outbreak, information has continually been updated and shifting over time with increased research. This brings about the challenge of disseminating the most updated information to the public so that their knowledge, attitudes, and behaviors are in line with the most recent recommendations [17]. Responses may range from being overly anxious to unconcerned. Either way, public perceptions have the capacity to influence actions in a way that can either alleviate or worsen the spread of an infectious disease like COVID-19. Thus, it is important to understand what public perceptions have been at a time when research is still at its inception and what the primary sources of information have been in order to understand how to best communicate scientific knowledge with the public.

The purpose of this study was to understand individuals' knowledge, attitudes, and beliefs on COVID-19 at a time when significant research was being conducted to influence guidelines and recommendations. This was particularly looking at a specific subset of the United States population, surveying women in Kansas when case rates in the state had been more stable than the months prior. 
Table 2 Assessment of participants' knowledge about COVID-19 ( $\mathrm{N}=305)$

\begin{tabular}{|c|c|c|c|}
\hline Statement & Correct, $\mathrm{n}(\%)$ & Incorrect, $\mathrm{n}(\%)$ & No answer, $\mathrm{n}(\%)$ \\
\hline The main clinical symptoms of COVID-19 are cough, shortness of breath, and fever (true) & $296(97.0)$ & $9(3.0)$ & $0(0.0)$ \\
\hline $\begin{array}{l}\text { Those who are elderly and have chronic illnesses are more likely to develop severe cases of } \\
\text { COVID-19 (true) }\end{array}$ & $299(98.0)$ & $6(2.0)$ & $0(0.0)$ \\
\hline COVID-19 is highly fatal (false) & $226(74.1)$ & $78(25.6)$ & $1(0.3)$ \\
\hline COVID-19 was created by humans (false) & $236(77.4)$ & 66 (21.6) & $3(1.0)$ \\
\hline $\begin{array}{l}\text { The COVID-19 virus spreads via respiratory droplets (from cough or exhalation) of infected } \\
\text { individuals (true) }\end{array}$ & $300(98.4)$ & $2(0.7)$ & $3(1.0)$ \\
\hline $\begin{array}{l}\text { Eating or touching animals is another main mechanism of spreading the COVID-19 virus } \\
\text { (false })\end{array}$ & $284(93.1)$ & $17(5.6)$ & $4(1.3)$ \\
\hline Infected individuals who don't feel sick can still infect others (true) & $299(98.0)$ & $3(1.0)$ & $3(1.0)$ \\
\hline Getting a flu shot will decrease your risk of developing COVID-19 (false) & $294(96.4)$ & $10(3.3)$ & $1(0.3)$ \\
\hline The COVID-19 virus lives for about an hour on surfaces (i.e. boxes) (false) & $166(54.4)$ & $134(43.9)$ & $5(1.6)$ \\
\hline Taking antibiotics is one way to prevent COVID-19 (false) & $297(97.4)$ & $4(1.3)$ & $4(1.3)$ \\
\hline The current treatment for COVID-19 is supportive care (true) & $230(75.4)$ & $72(23.6)$ & $3(1.0)$ \\
\hline Vitamin C can help treat COVID-19 (false) & $249(81.6)$ & $50(16.4)$ & $6(2.0)$ \\
\hline There is currently an effective vaccine against COVID-19 available (false) & $300(98.4)$ & $3(1.0)$ & $2(0.7)$ \\
\hline
\end{tabular}

Table 3 Assessment of participants' attitude towards and beliefs about COVID-19 (N=305)

\begin{tabular}{|c|c|c|c|c|c|c|}
\hline Statement & $\begin{array}{l}\text { Strongly } \\
\text { Disagree, n } \\
(\%)\end{array}$ & Disagree, $\mathrm{n}(\%)$ & Neutral, n (\%) & Agree, n (\%) & Strongly Agree, n (\%) & Missing, $\mathrm{n}(\%)$ \\
\hline $\begin{array}{l}\text { I believe COVID-19 will be successfully } \\
\text { controlled this year }\end{array}$ & $83(27.2)$ & $132(43.3)$ & $46(15.1)$ & $35(11.5)$ & $6(2.0)$ & $3(1.0)$ \\
\hline $\begin{array}{l}\text { COVID-19 presents a serious threat to the } \\
\text { public }\end{array}$ & $10(3.3)$ & $15(4.9)$ & $15(4.9)$ & $80(26.2)$ & $183(60.0)$ & $2(0.7)$ \\
\hline I believe the outbreak will get worse & $9(3.0)$ & $19(6.2)$ & $36(11.8)$ & $117(38.4)$ & $124(40.7)$ & $0(0.0)$ \\
\hline $\begin{array}{l}\text { I am confident that the U.S. will win the } \\
\text { battle against the COVID-19 virus }\end{array}$ & $18(5.9)$ & $54(17.7)$ & $83(27.2)$ & $109(35.7)$ & $41(13.4)$ & $0(0.0)$ \\
\hline $\begin{array}{l}\text { I think the response to the COVID-19 } \\
\text { pandemic has been overblown }\end{array}$ & $168(55.1)$ & $61(20.0)$ & $33(10.8)$ & $22(7.2)$ & $21(6.9)$ & $0(0.0)$ \\
\hline I am not worried about my personal health & $118(38.7)$ & $114(37.4)$ & $36(11.8)$ & $28(9.2)$ & $9(3)$ & $0(0.0)$ \\
\hline $\begin{array}{l}\text { I am not worried about my friends' and } \\
\text { family members' health }\end{array}$ & $149(48.9)$ & $104(34.1)$ & $29(9.5)$ & $13(4.3)$ & $5(1.6)$ & $5(1.6)$ \\
\hline $\begin{array}{l}\text { I think social distancing is an effective } \\
\text { way of controlling COVID-19 spread }\end{array}$ & $3(1.0)$ & $7(2.3)$ & $30(9.8)$ & 133 (43.6) & $132(43.3)$ & $0(0.0)$ \\
\hline $\begin{array}{l}\text { I am confident in the healthcare system's } \\
\text { ability to control the virus }\end{array}$ & $16(5.2)$ & $60(19.7)$ & $92(30.2)$ & $114(37.4)$ & $22(7.2)$ & $1(0.3)$ \\
\hline I am afraid of going to the doctor & $114(37.4)$ & $111(36.4)$ & $39(12.8)$ & $32(10.5)$ & $8(2.6)$ & $1(0.3)$ \\
\hline
\end{tabular}

Participants of this study had fairly good knowledge of COVID-19 and SARS-CoV-2 with an average score of 11.40 out of 13 . Given that their most common primary sources of information came from health officials and healthcare professionals, which is where the current knowledge is based off of, this pattern makes sense. The question that seemed to have been the most challenging for participants was how long the virus lasts on surfaces. This was a question that was disputed throughout the first few months of the pandemic (more so than, for example, taking antibiotics to treat COVID-19) [18]. Thus it implies that knowledge on a topic is dependent on the consistency with which a certain fact is relayed. Other more definitively false statements, such as SARS-CoV-2 being manufactured by humans, vitamin $\mathrm{C}$ treating COVID-19, and COVID-19 having a high fatality rate, still presented with a decent number of individuals answering "true." These beliefs, though the scientific data at the time did not support it, still persisted in the population, indicating the capability of misinformation to spread.

The general attitude of participants seemed to be that of caution without being overly fearful or overly unconcerned. Of course, there were still outliers who did not believe 
Table 4 Assessment of participants' behaviors in response to COVID-19 ( $=305)$

\begin{tabular}{|c|c|c|c|c|c|c|}
\hline Statement & Never, n (\%) & Rarely, n (\%) & Sometimes, n (\%) & Often, n (\%) & Always, n (\%) & Missing, $\mathrm{n}(\%)$ \\
\hline I avoid going to crowded places & $5(1.6)$ & $5(1.6)$ & $24(7.9)$ & $88(28.9)$ & $180(59.0)$ & $3(1.0)$ \\
\hline I avoid leaving my home & $18(5.9)$ & $46(15.1)$ & $92(30.2)$ & $128(42)$ & $21(6.9)$ & $0(0.0)$ \\
\hline I avoid traveling & $13(4.3)$ & $14(4.6)$ & $44(14.4)$ & $95(31.1)$ & $136(44.6)$ & $2(1.0)$ \\
\hline I cancel or postpone doctor's appointments & $102(33.4)$ & $99(32.5)$ & $63(20.7)$ & $24(7.9)$ & $15(4.9)$ & $2(0.7)$ \\
\hline I wear a mask when leaving my home & $10(3.3)$ & $2(0.7)$ & $16(5.2)$ & $41(13.4)$ & $234(76.7)$ & $2(0.7)$ \\
\hline $\begin{array}{l}\text { I wash my hands thoroughly with soap and water } \\
\text { often }\end{array}$ & $1(0.3)$ & $0(0.0)$ & $9(3.0)$ & $66(21.6)$ & $228(74.8)$ & $1(0.3)$ \\
\hline $\begin{array}{l}\text { I try to stay six feet away from people (outside of } \\
\text { those I live with) }\end{array}$ & $2(0.7)$ & $4(1.3)$ & $12(3.9)$ & $65(21.3)$ & $219(71.8)$ & $3(1.0)$ \\
\hline I avoid close contact with those who are sick & $2(0.7)$ & $2(0.7)$ & $3(1.0)$ & $23(7.5)$ & $271(88.9)$ & $4(1.3)$ \\
\hline $\begin{array}{l}\text { I avoid getting food from outside (takeout/deliv- } \\
\text { ery) }\end{array}$ & $54(17.7)$ & $80(26.2)$ & $94(30.8)$ & $55(18.0)$ & $22(7.2)$ & $0(0.0)$ \\
\hline I avoid eating meat & $186(61.2)$ & $71(23.3)$ & $21(6.9)$ & $21(6.9)$ & $5(1.6)$ & $1(0.3)$ \\
\hline I disinfect my groceries and mail & $117(38.4)$ & $71(23.3)$ & $68(22.3)$ & $26(8.5)$ & $22(7.2)$ & $1(0.3)$ \\
\hline I take an herbal supplement & $147(48.2)$ & $36(11.8)$ & $34(11.1)$ & $33(10.8)$ & $52(17.4)$ & $2(0.7)$ \\
\hline
\end{tabular}

Fig. 1 Participants' primary sources of information $(\mathrm{N}=305)$

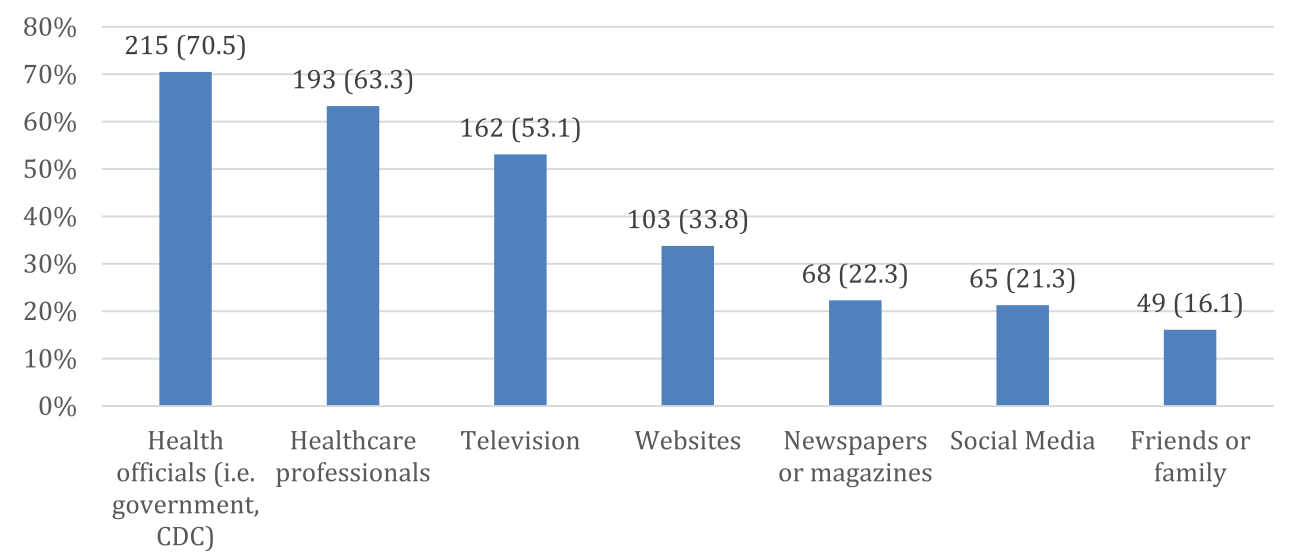

Overall, the participants of this study had good knowledge of COVID-19 and exemplified a more cautious attitude towards it. This also manifested in their indicated behaviors which aligned well with the given guidelines at the time this survey was administered. The more heavily used sources of information for these participants were those that tend to be more credible, such as health officials and healthcare professionals, as opposed to the potentially less credible sources of social media and friends or family. These findings align well with the prior study on Kansans' perception, knowledge, and compliance that found that participants' most trusted source was healthcare workers. This study also demonstrated Kansans above average understanding of COVID-19 and high compliance with preventative practices [6].

\section{Limitations and Future Directions}

While this study is meant to represent the stances of Kansas women, it is not representative of the entire population. 
The majority of participants were white women who were above the age of 50 and had a condition that put them at risk for COVID-19 complications. All these factors may bias participant responses. For example, an older population who is more at risk of contracting a severe case of COVID-19 is likely to be less risky in their behaviors and perceptions of COVID-19 [20]. Future studies should include more individuals who are younger as well as include more ethnic, racial, and income diversity in order to account for all Kansan women.

The next limitation of this study is that it only represents one timepoint during the entire pandemic. While the survey was administered during a time when case rates were more stable in Kansas in order to minimize the impact of environment on responses, these responses will inevitably change with changing circumstances. Longitudinal studies examining these same criteria at different timepoints during the pandemic may be beneficial for understanding the fluctuating responses with fluctuating pandemic circumstances.

Finally, with regards to the behavior component of this survey, responses only represent reported behaviors of participants. There is no way of knowing whether participants are actually practicing said behaviors with the consistency that they state. There may be a discrepancy between individuals' perceived practices and actual practices that this study does not take into account.

\section{Conclusions}

Despite generally good knowledge of the current pandemic, misinformed beliefs (as well as attitudes and behaviors based on those beliefs) still exist. Information sources should consider the impact they have on influencing the public response to the pandemic, which can have ramifications at both an individual and public level.

\footnotetext{
Author Contributions CM conceived of the presented idea. TB carried out the project and wrote the manuscript with the help and guidance of CM.
}

Funding This research received no external funding.

Data Availability The corresponding author may be contacted for all material used and data obtained from this study.

\section{Declarations}

Conflict of interest The authors have no conflicts of interest to disclose.
Ethical approval This project was approved for submission by the University of Kansas Medical Center Human Research Protection Program. The IRB number for reference is STUDY00145846.

Informed Consent Participants were emailed details regarding the voluntary nature, anonymity, and purpose of the study. Along with the link to the survey, they were told that participation in the survey was considered consent.

\section{References}

1. World Health Organization. (2020). Timeline of WHO'S response to COVID-19. WHO. https://www.who.int/news/item/29-06-2020covidtimeline

2. World Health Organization. (2020). WHO Director-General's opening remarks at the media briefing on COVID-19. WHO. https://www.who.int/director-general/speeches/detail/who-direc tor-general-s-opening-remarks-at-the-media-briefing-on-covid19---11-march-2020\#: :text=WHO\%20has\%20been\%20assessing\%20this,to\%20use \%20lightly\%20or\%20carelessly.

3. Steffens, I. (2020). A hundred days into the coronavirus disease (COVID-19) pandemic. European Communicable Disease Bulletin, 25(14), 2000550

4. Ajilore, K., Atakiti, I., \& Onyenankeya, K. (2017). College students' knowledge, attitudes and adherence to public service announcements on Ebola in Nigeria: Suggestions for improving future Ebola prevention education programmes. Health Education Journal, 76(6), 648-660

5. Kelly, B., Squiers, L., Bann, C., Stine, A., Hansen, H., \& Lynch, M. (2015). Perceptions and plans for prevention of Ebola: results from a national survey. BMC Public Health, 15, 1136

6. Geana, M. V. (2020). Kansans in the middle of the pandemic: Risk perception, knowledge, compliance with preventive measures, and primary sources of information about COVID-19. Kansas Journal of Medicine, 13, 160-164

7. Centers for Disease Control and Prevention. Compare trends in COVID-19 cases and deaths in the US. CDC. Accessed 2020 December 13.

8. Zhong, B. L., Luo, W., Li, H. M., Zhang, Q. Q., Liu, X. G., Li, W. T., \& Li, Y. (2020). Knowledge, attitudes, and practices towards COVID-19 among Chinese residents during the rapid rise period of the COVID-19 outbreak: a quick online cross-sectional survey. International Journal of Biological Sciences, 16(10), 1745-1752

9. McFadden, S. M., Malik, A. A., Aguolu, O. G., Willebrand, K. S., \& Omer, S. B. (2020). Perceptions of the adult US population regarding the novel coronavirus outbreak. PLOS ONE, 15(4), e0231808

10. Kamate, S. K., Sharma, S., Thakar, S., et al. (2020). Assessing knowledge, attitudes and practices of dental practitioners regarding the COVID-19 pandemic: A multinational study. Dental and Medical Problems, 57(1), 11-17

11. Bhagavathula, A. S., Aldhaleei, W. A., Rahmani, J., Mahabadi, M. A., \& Bandari, D. K. (2020). Knowledge and perceptions of COVID-19 among health care workers: Cross-sectional study. JMIR Public Health and Surveillance, 6(2), e19160

12. Geldsetzer, P. (2020). Use of rapid online surveys to assess people's perceptions during infectious disease outbreaks: A crosssectional survey on COVID-19. Journal of Medical Internet Research, 22(4), e18790

13. Roy, D., Tripathy, S., Kar, S. K., Sharma, N., Verma, S. K., \& Kaushal, V. (2020). Study of knowledge, attitude, anxiety \& 
perceived mental healthcare need in Indian population during COVID-19 pandemic. Asian Journal of Psychiatry, 51, 102083

14. Khader, Y., Al Nsour, M., Al-Batayneh, O. B., et al. (2020). Dentists' awareness, perception, and attitude regarding COVID-19 and infection control: Cross-sectional study among Jordanian DENTISTS. JMIR Public Health and Surveillance, 6(2), e18798

15. Wolf, M. S., Serper, M., Opsasnick, L., et al. (2020). Awareness, attitudes, and actions related to COVID-19 among adults with chronic conditions at the onset of the U.S. outbreak: A crosssectional survey. Annals of Internal Medicine, 173(2), 100-109

16. Abdelhafiz, A. S., Mohammed, Z., Ibrahim, M. E., Ziady, H. H., Alorabi, M., Ayyad, M., \& Sultan, E. A. (2020). Knowledge, perceptions, and attitude of Egyptians towards the novel coronavirus disease (COVID-19). Journal of Community Health, 45(5), 881-890

17. Centers for Disease Control and Prevention. Coronavirus disease: Frequently asked questions. $C D C$. Updated 2020 December 11. https://www.cdc.gov/coronavirus/2019-ncov/faq.html\#Basics
18. Goldman, E. (2020). Exaggerated risk of transmission of COVID19 by fomites. The Lancet. Infectious Diseases, 20(8), 892-893

19. Taylor, S., \& Asmundson, G. (2021). Negative attitudes about facemasks during the COVID-19 pandemic: The dual importance of perceived ineffectiveness and psychological reactance. $P L O S$ ONE, 16(2), e0246317

20. Canning, D., Karra, M., Dayalu, R., Guo, M., \& Bloom, D. E. (2020). The association between age, COVID-19 symptoms, and social distancing behavior in the United States. Health Sciences. https://doi.org/10.1101/2020.04.19.20065219

Publisher's Note Springer Nature remains neutral with regard to jurisdictional claims in published maps and institutional affiliations. 